\title{
A Networked Analysis and Engineering Framework for New Business Models
}

\author{
Wolfgang Vorraber ${ }^{1, *(D)}$ and Matthias Müller ${ }^{2}$ (D) \\ 1 Institute of Engineering and Business Informatics, Graz University of Technology, 8010 Graz, Austria \\ 2 Institute of Software Technology, Graz University of Technology, 8010 Graz, Austria; mueller@ist.tugraz.at \\ * Correspondence: wolfgang.vorraber@tugraz.at; Tel.: +43-316-873-8004
}

Received: 16 August 2019; Accepted: 23 October 2019; Published: 29 October 2019

\begin{abstract}
New technological possibilities and paradigm shifts from product-centered to service-centered offerings are one of the main drivers of business models. Business ventures today are more and more networked. Often, various partners are needed to deliver a service or product to frequently cross-linked customers with sometimes bi- or even multi-variant roles. Furthermore, business models are embedded in socio-technical systems where different kinds of needs and values of all actors, including social, ecological, technical and economic values, have to be balanced. The resulting complex network of actors, needs and values requires continuous management in order to create and operate viable and sustainable business models. This paper proposes a multi-layer framework to analyze existing business models as well as to shape new business ventures in a networked and values-based way and to support the identification of tacit network effects within business ecosystems. Based on an existing multi-layered analysis toolkit, focusing on legal and business dynamics aspects, an enhanced visualization and analysis tool is proposed that focuses especially on ethical, social and environmental aspects to foster the creation of (strongly) sustainable business models. The research process to create the presented approach followed the Design Science Research paradigm by applying argumentative-deductive analysis (ADA) and first applications in real-world case studies. A practical case from an international Open Source Software (OSS) project serves as an example to illustrate this values-based visualization and analysis layer and its benefits for managers and decision makers in the area of business model and information system management.
\end{abstract}

Keywords: information systems engineering; business model innovation; sustainable business models; design science research

\section{Motivation}

The general goals of business model innovation and information systems engineering are to improve business processes of service providers (value creation) and to support tasks of users and customers to ultimately meet the goals of these multiple stakeholders (value proposition) while ensuring economic viability (value capture) [1-4]. New digital artifacts such as new information systems are embedded into socio-technical systems (STS) consisting of human, organizational, technological and social structures, which are enclosed by a societal context [5-7]. Beside general aims of participants in a business ecosystem such as monetary or other types of profit, the wide spread awareness of ecological challenges accompanied by recent developments in the area of ecological movements and their claim for sustainable development [8] fosters the need for strongly sustainable business models [9] (also denoted as New Business Models (NBM) [10,11]) and a general inclusion of these needs into approaches to design and manage their business models. In this regard, we follow Upward and Jones [9] (p. 17) and use the terms sustainable or strongly sustainable in conjunction with business models synonymously to emphasize the striving for " [... simultaneously 
creating financial rewards, social benefits, and environmental regeneration". Furthermore, the different values and needs that have to be considered to succeed in ecosystem management do not solely cover economic and ecological aspects. Also ethical needs of stakeholders have to be taken into account. Unmet ethical needs may bring whole projects at risk or may even lead to complete failures, as an abandoned Dutch electronic patient record system project showed in 2011 [12]. By not succeeding to properly include the key need of privacy of end users in the design of the business model and the underlying information system, the project resulted in a $€ 300$ million loss. Therefore, to be able to design, engineer, deploy and manage digital artifacts and their business models in a complex STS, detailed insights into the needs of all participating actors are required [13]. Knowledge of the needs of each actor is essential to determine satisfiers for their needs. The needs and satisfiers concept is based on Max-Neef et al. [14], who created a generic concept for the relation between human needs and ways of satisfying these needs, denoted as satisfiers. It is important to identify the desires of each participant in an ecosystem, which is essential to arrange a viable business model ecosystem. The presented framework supports identifying and modeling the needs of the participants of an ecosystem and consequently to gain insights on the motivation levels of each participant to contribute to the ecosystem. These motivation levels affect the emergent behavior of socio-technical systems, which make them to a crucial aspect to analyze and manage business ecosystems.

Needs of users can be diverse and can have their roots in fundamental and general forms, as described by Max-Neef [14], such as subsistence, protection, affection, creation and identity. Especially relevant for the focus of this article are the basic needs affection and identity, because they deal with aspects such as "relationship with nature", "values" and "norms" [14]. In addition to fundamental needs, the enhanced framework proposed in this paper also facilitates the modeling and analyzing of task or job related needs seen from a STS perspective. Here, the ecosystem is intended to satisfy work or task related needs of specific actors, while preserving viable business models for each contributing actor. Examples therefore can be information systems that support actors in accomplishing tasks more efficiently, while simultaneously generating satisfiers in return for actors providing or enabling this information system. Furthermore, as described by Max-Neef ([14], p. 17) "[a] satisfier may contribute simultaneously to the satisfaction of different needs or, conversely, a need may require various satisfiers in order to be met."

The need for holistic and sustainable innovation is also highlighted by engineering and business driven research areas. As an example, Böhmann et al. [15] lined out future research directions in information systems engineering by stating, "[...] that the combination and integration of social, technological, economic and even societal design elements will become even more relevant in future" ([15], p. 374). Current developments in the area of sustainable business models go in line with this statement. Future business models should not solely focus on monetary aspects of services, but also include non-pecuniary needs of users and society $[9,16,17]$. The framework presented aims to support the generation of sustainable business models and their corresponding information systems by targeting the following two goals:

- Inclusion and management of social, technological, economic and ecological aspects in information systems engineering to foster service design, aiming at ensuring successful integration and acceptance of digital artifacts in STSs.

- Fostering sustainable business model analysis and design by providing multifaceted insights into needs of users and service providers, legal constraints and dynamics of value exchanges.

\section{Introduction}

In this paper, we propose a tool that is intended to support the modeling and analysis of sustainable business models by facilitating a networked perspective on the business model, its actors and the values and needs of these actors. With regard to the creation of sustainable business models, it is important to know and represent the values of the actors and how they are met in the overall context of the business network. The values and needs layer proposed in this paper, and also the other layers 
presented, which are built upon existing concepts and enhance them in selected aspects, have been developed in the domain of information system projects. The values and needs layer is intended to support the analysis of the needs and satisfiers of actors in a business context. It may serve information system designers and also business model designers to gain insights into the values of the actors in a business network. In the context of business models, and especially in the area of sustainable business models, this networked perspective supported by the values and needs modeling tool may provide useful insights for managers. As shown in more detail in Section 3, existing sustainable business models are often represented in a component-based and not networked way. This type of representation provides a very valuable and abstract view on a business model, but may also run at risk to miss important aspects of a complex system such as a business model. In this regard, we also refer to Massa et al. [18], who stated that "[w] believe that much is to be gained by moving beyond a discussion of BMs [business models] that focuses on its static representation and rather starting to theorize on the interdependencies" ([18], p. 64). They categorized business models as complex systems and pointed out that "[t]he more we move from simpler to more complex system, the less the level of the static framework is sufficient in providing a comprehensive picture that would allow understanding the system" ([18], p. 63). The network perspective on values and needs proposed in this paper and the other layers presented, allow grasping selected aspects of elements and dependencies of a business model, which are important for the analysis of complex systems. Furthermore, Massa et al. [18] listed aspects of business models that are important for analysis and concluded as follows: "[... ] the more we move toward systems of increased complexity, the more we need to account for aspects such as the role of information flows and interpretation, purposefulness and intentionality, and, in general, complex interdependencies, if we are to understand how such systems ultimately work. As we propose below, these aspects have largely been ignored within the literature on the BM" ([18], p. 62). Similarly, Biloslavo et al. [19] (p. 761) pointed out the need for future research in this area by stating: "While some advances have been made in consolidating and beginning to understand the state of the art in BM research, there is still a gap relating to the sustainability and eco-agenda, and the need to develop the understanding of co-operation, co-creation and values as vehicles to deliver a sustainability driven BM." While being aware that the tool presented in this paper is not fully able to represent and analyze a complex system such as a business model on a fine grained level, the networked perspective on the values and needs of actors may contribute to the existing literature, which mainly focuses on component-based forms of abstraction. Furthermore, the networked representation proposed may serve as a basis for more detailed modeling and analysis forms such as agent-based modeling (ABM) and the simulation of scenarios based on these models. This would enable to grasp insights on emergent behavior inherent to complex business model systems, based on quantitative approaches.

This paper is structured as follows. Sections 1 and 2 provide an overview on the motivation for this paper and a general introduction to the main theoretical concepts underlying this paper. Section 3 focuses on the targeted main research area of sustainable business models. It provides an overview on important related work in this field and points out the need for a tool which supports the networked representation and analysis of values in sustainable business models, thereby complementing existing frameworks. Section 4 embeds the presented research in a larger multidisciplinary context by providing an overview of related research fields targeting also sustainable development based on different scientific backgrounds. Section 5 provides an overview of the research method applied and also discusses limitations of this work. Section 6 presents the new values and needs layer proposed in this paper in the context of already existing layers. These already published layer concepts [20-22] are also described briefly to present the framework in its entirety and to illustrate the benefits of this integrated framework. Section 7 illustrates the application of the proposed values and needs layer with a concrete example in form of a real-world business model in the open source domain. Sections 8 and 9 provide a discussion and an outlook of the work presented. Furthermore, Figure 1 illustrates the applied research method and includes references to the sections, which describe the corresponding aspects in more detail. 


\section{The Need for a Networked Values-Based Modeling Tool Complementing Existing Frameworks}

Conventional graphical business model frameworks such as the Business Model Canvas (BMC) [2] serve well to structure basic building blocks of business models from an ego-centric perspective [23]. These concepts also facilitate the communication process about business models on an abstracted level. However, business models are more and more connected, which requires also a shift to network-centric tools and frameworks for business model engineering [9,16,24]. Although graphical business model frameworks are powerful tools through their simplicity, their still rather high level of abstraction results in their weakness of presenting an in-depth understanding of the dynamics and network externalities of business models, which can especially occur in sustainable business models [25]. Consequently, they lack in representing complex systems, which increasingly include social components such as human interactions, organizations or the society [18]. Although current business model representations in the field of sustainability highlight the importance of networked effects, i.e., their dynamics and complexity, they hardly provide a visual and easy to use representation of them. We complement these frameworks by providing this complexity perspective, as highlighted by Massa et al. [18].

Widely spread graphical frameworks for business model and service design, such as the Business Model Canvas [2], focus on customers and in certain cases also on needs of providers [26]. The needs covered by these frameworks emphasize functional and non-functional aspects which support customer's processes. Despite some general notices (e.g., the Value Proposition Canvas [3] indirectly mentions ethical aspects), and the component based framework of Ojasalo and Ojasalo [26], ethical and ecological values are hardly covered in established business model innovation frameworks in a holistic way. As a consequence, research strands such as the NBM community strived for frameworks that support the creation of strongly sustainable firms, which was defined by Upward and Jones [9] (p. 103) "[... as an organization that only enabled strongly sustainable outcomes as one that creates positive environmental, social and economic value throughout its value network, thereby sustaining the possibility that human and other life can flourish on this planet forever (Ehrenfeld [27]; Willard et al. [28])". As a recent analysis of Breuer et al. [29] referenced by Glinik and Vorbach [30] shows, frameworks such as the Strongly Sustainable Business Model Canvas [31], the Value Mapping Tool [16], the Values-based Innovation Framework [17,24], the Sustainable Business Canvas [32], the Triple Layered Business Model Canvas [33], and the Business Model Canvas (BMC) approach extended for infrastructure [34] are explicitly targeting this new research field. These frameworks mainly foster the initial step of sustainable business model innovation processes by providing high-level workshop formats and component based business model visualization tools. This leaves room for frameworks that support required iterations after first high-level workshops, focusing on the networked values constellations of sustainable business models. Table 1 provides an overview of an analysis of common sustainable business model frameworks. The selection of the frameworks is based on [29] and is enhanced by the Value Triangle (VT) and VT Business Model Canvas [19], and the visual coding scheme developed by Brehmer et al. [35], herein after referred to as Visual Coding Scheme for Sustainable Business Models. The analysis is structured according to the following criteria:

- Network perspective: As indicated above, business model innovation frameworks need to take a network-centric perspective on the entire ecosystem of actors co-creating value propositions, rather than focusing on a single firm or actor (ego-centric). Regarding this aspect, we analyzed if the framework includes a network perspective as a conceptual or theoretical underpinning depicted as "implicit" and if this network perspective is also represented in the visualization of the framework, depicted as "explicit".

- Type of visual representation: According to the categorization of visualization forms of business model frameworks of Täuscher and Abdelkafi [36], we structured this criterion into:

- Elements or component based view: A typical example for this form of business model frameworks is the BMC where predefined tiles provide a basic static structure to be filled. According to Täuscher and Abdelkafi [36] (pp. 164f), a framework "[...] is assigned to the 
elements view when it contains a specific specification of different business model elements, or if it represents a template to be filled out with such information."

- Transactional view: This category is characterized by elements representing actors or stakeholders of a business model and arrows in between them which represent value exchanges [36]. Typical examples thereof are value network notations such as $\mathrm{e}^{3}$ Gordijn et al. [37], Allee's framework [38] or Biem and Caswell's value network notation [39]. However, as stated by Breuer and Lüdeke-Freund [17] (p. 162):

"While the traditional view of value networks focuses on the creation of competitive advantages and economic value for network members, it does not consider their notions of the desirable and normative orientations, which may motivate the formation and persistence of networks, or which may lead to their collapse in the case of diverging and incompatible values. Although the value network framework by Allee $(2000,2011)$, as a prominent example, extends the notion of value to account for the exchange of goods and services, knowledge, and intangible benefits such as customer loyalty or image enhancement, it does not include the underlying value commitments and normative orientations of exchange partners."

- Causal view: In this category, elements are connected by arrows, which represent causal connections [36]. Business model representations are assigned to this category if "[...] the visual representation reveal [s] major causalities between the textual elements" [36] (p. 166).

- Stakeholder needs and satisfiers: As described by Breuer and Lüdeke-Freund [17] (p. 162) referring to Peppard and Rylander [40] (p. 135) "[p]erceived value is a key driver of behaviour which in turn is a key force of network development." By explicitly representing the needs and the satisfiers of an actor, the perceived value may be anticipated and visually represented. As described by Täuscher and Abdelkafi [36], visual representation of business model systems supports experts to cope with complexity and analyze the relationships of a system [41,42]. Furthermore, Täuscher and Abdelkafi [36] highlighted that it frees cognitive processing power [43] and fosters communication with other experts on different organizational levels and external stakeholders [44]. Therefore, the visual representation of values, their satisfiers and the level of needs met is seen as important for analyzing values-based networks and as a consequence is included into the analysis structure of existing NBMs as follows:

- Explicating needs: The needs of the actors or stakeholders are explicitly represented in a visual form.

- Explicating satisfiers and needs met: The satisfiers and results of satisfiers as level of needs met are explicitly represented in a visual form. 
Table 1. Analysis of existing NBM innovation frameworks (selection of frameworks based on Breuer et al. [29]).

\begin{tabular}{|c|c|c|c|c|c|c|c|}
\hline \multirow[t]{2}{*}{ Framework } & \multicolumn{2}{|c|}{ Network Perspective } & \multicolumn{3}{|c|}{ Type of Representation } & \multicolumn{2}{|c|}{ Stakeholder Needs } \\
\hline & Implicit & Explicit & Component Based & Transaction Based & Causality Based & Explicating Needs & Explicating Satisfiers \\
\hline $\begin{array}{l}\text { Strongly Sustainable } \\
\text { Business Model } \\
\text { Canvas [31] }\end{array}$ & $\begin{array}{l}\text { business' value } \\
\text { network [31] (p. 2) }\end{array}$ & - & yes & - & - & $\begin{array}{l}\text { visualization not } \\
\text { networked }\end{array}$ & $\begin{array}{l}\text { through value } \\
\text { propositions [31] (p. 5) } \\
\text { visualization not } \\
\text { networked }\end{array}$ \\
\hline $\begin{array}{l}\text { Value Mapping } \\
\text { Tool [16] }\end{array}$ & $\begin{array}{l}\text { stakeholder network } \\
{[16] \text { (pp. 485, 488) }}\end{array}$ & $\begin{array}{l}\text { stakeholder groups [16] } \\
\text { (pp. 489f), but no } \\
\text { networked representa- } \\
\text { tion [16] (p. 488) }\end{array}$ & yes & - & - & $\begin{array}{l}\text { implicit in value } \\
\text { dimensions [16] (p. 488) }\end{array}$ & $\begin{array}{l}\text { implicit in value } \\
\text { dimensions [16] } \\
\text { (p. 488), visualization } \\
\text { not networked }\end{array}$ \\
\hline $\begin{array}{l}\text { Values-based } \\
\text { Innovation }[17,24]\end{array}$ & $\begin{array}{l}\text { network of actors [24] } \\
\text { (pp. 1ff) }\end{array}$ & $\begin{array}{l}\text { networked structure } \\
{[24](\text { p. 16) }}\end{array}$ & $\begin{array}{l}\text { yes, in the Business } \\
\text { Innovation Kit [17] } \\
\text { (p. 194) }\end{array}$ & - & - & $\begin{array}{l}\text { implicit in [24] (pp. 15f), } \\
\text { visualization of needs } \\
\text { not networked }\end{array}$ & $\begin{array}{l}\text { implicit [24] (p. 16), } \\
\text { visualization not } \\
\text { networked }\end{array}$ \\
\hline $\begin{array}{l}\text { Sustainable Business } \\
\text { Canvas [32] }\end{array}$ & $\begin{array}{l}\text { analysis of environ- } \\
\text { ment [32] (p. 6) }\end{array}$ & - & $\begin{array}{l}\text { representation in [32] } \\
\text { (p. 7) }\end{array}$ & - & - & $\begin{array}{l}\text { questions in [32] (p. 12), } \\
\text { no explicit modeling }\end{array}$ & $\begin{array}{l}\text { questions in [32] } \\
\text { (pp. 10,12), no explicit } \\
\text { modeling }\end{array}$ \\
\hline $\begin{array}{l}\text { Triple Layered Business } \\
\text { Model Canvas [33] }\end{array}$ & - & - & yes [33] (p. 1483) & - & - & $\begin{array}{l}\text { through value } \\
\text { proposition [33] } \\
\text { (p. 1481), visualization } \\
\text { not networked }\end{array}$ & $\begin{array}{l}\text { indirect in value } \\
\text { proposition and social } \\
\text { stakeholder layer [33] } \\
\text { (p. 1481), no } \\
\text { networked } \\
\text { visualization }\end{array}$ \\
\hline $\begin{array}{l}\text { BMC extended for } \\
\text { infrastruc- ture [34] }\end{array}$ & $\begin{array}{l}\text { STS, actors, networks } \\
\text { [34] (p. 4) }\end{array}$ & - & yes [34] (p. 10) & - & - & $\begin{array}{l}\text { value proposition [34] } \\
\text { (p. 10), no networked } \\
\text { visualization }\end{array}$ & $\begin{array}{l}\text { value proposition and } \\
\text { stream extensions [34] } \\
\text { (p. 10), no networked } \\
\text { visualization }\end{array}$ \\
\hline $\begin{array}{l}\text { Value triangle and VT } \\
\text { BMC [19] }\end{array}$ & $\begin{array}{l}\text { co-creation [19] } \\
\text { (pp. 755f) }\end{array}$ & - & yes [19] (pp. 755ff) & - & - & $\begin{array}{l}\text { through value } \\
\text { propositions [19] } \\
\text { (pp. 755ff), no } \\
\text { networked } \\
\text { visualization }\end{array}$ & $\begin{array}{l}\text { through value } \\
\text { propositions [19] } \\
\text { (pp. 755ff), no } \\
\text { networked } \\
\text { visualization }\end{array}$ \\
\hline $\begin{array}{l}\text { Visual Coding Scheme } \\
\text { for Sustainable } \\
\text { Business Models [35] }\end{array}$ & $\begin{array}{l}\text { boundary-spanning } \\
\text { perspective [35] } \\
\text { (p. 4514) }\end{array}$ & yes [35] (p. 4517) & - & yes [35] (p.4516) & - & - & $\begin{array}{l}\text { implicit through value } \\
\text { transfer [35] (p. 4516) }\end{array}$ \\
\hline
\end{tabular}


In the performed analysis, we identified several similarities, differences and the need for an explicit networked and values-based modeling tool as follows:

The Strongly Sustainable Business Model Canvas [31] is based on a network-centric perspective on a business model, but does not explicitly visually represent it. This framework follows a component based type of visualization. Regarding the criteria of explicating stakeholder needs, the framework explicitly mentions needs in the course of guiding questions [31] (p. 5), but there is no explicit guiding structure despite human and non-human actors' fundamental needs. Task or business related needs are not explicitly mentioned. The framework visually represents needs in a component based and not networked way. With guiding questions about the value propositions, such as "How does each value proposition relate to meeting an actor's need or might prevent an actor from fulfilling a need?", the framework deals with needs and satisfiers. Analog to the needs, this aspect is also represented in a component based and not networked way.

The Value Mapping Tool by Bocken et al. [16] includes a network perspective as a theoretical underpinning becoming obvious with pointing out the need for a networked perspective [16] (pp. 485, 488). It does not visually represent value exchanges in a detailed way. The visualization provided by Bocken et al. [16] (p. 488) illustrates the value proposition of the network in the center, but does not represent each value exchange and the value propositions in a networked way. Furthermore, stakeholders are grouped "to facilitate a multiple stakeholder view of value." [16] (p. 489). The value mapping tool follows a component based visual representation and does not represent needs of actors visually. It includes various types of values and also the concept of perceived and actual values as a textual representation in the simplified value mapping tool [16] (p. 491), but not in a networked way.

The Values-based Innovation Framework [17,24] clearly points out the importance of a network of actors that contributes to a BM [24] (pp. 1ff). The visualization in [24] (p. 16) shows a networked structure of business model components, business models of actors, and values and normative orientations on a very high and schematic level. The intention of this illustration is to show "[...] how values-based networks are centered on shared values and normative orientations, while the participating actors pursue these within their different business models and business model components" [24] (p. 15). This points out the networked character of business models. The Business Innovation Kit [17] (p. 194) follows a component based visual representation. Furthermore, a visual representation of a business ecosystem in [24] (p. 21) includes actors and lines between the actors, but without transactions or directed causal relations. Stakeholder needs and satisfiers were implicitly covered by Breuer and Lüdeke-Freund [24] (pp. 15f) by proposing "[... the formation of values-based networks consisting of viable and sustainability-oriented business models. This requires a synthesis and careful definition of not only the values and normative orientations of all network stakeholders, but also the multiple value propositions offered to them and the valuable outcomes created with and for them." The visual representations specified in $[17,24]$ do not explicitly visualize needs and satisfiers in a dedicated and networked way.

The Sustainable Business Canvas [32] is based on an ego-centric perspective and is consequently not visualized in a networked way. The framework is represented in a component-based form. Regarding the criteria of explicating needs, our analysis indicated no explicit visual modeling. However, textual questions are included in the framework such as [32] (p. 12) "Does your business model generate additional value for other stakeholders, or can additional actors' needs which have not been satisfied so far be taken into account and utilized?" can be interpreted to target this aspect. Analog to this, the questions "Describe the positive impacts of your products and services on the environment and society [...]" [32] (p. 10) or "For which value are your customers really willing to pay for? How high is your customers' willingness to pay?" [32] (p. 12) can be interpreted to aim to cover the concepts of satisfiers and needs met partially. Nevertheless, there is no explicit visual modeling of it.

The Triple-Layered Business Model Canvas by Joyce and Paquin [33] does not mention a network-centric perspective as a conceptual underpinning and consequently does not represent a networked perspective visually. Similar to the Sustainable Business Canvas of Tiemann and Fichter [32], it is component based in its framework representation. Needs and satisfiers 
can be interpreted as implicitly included for end users in the value proposition aspect based on the following paragraph:

"The end-user is the person who 'consumes' the value proposition. This space is concerned with how the value proposition addresses the needs of the end-user, contributing to his/her quality of life. Users with similar needs have typically been segmented based on relevant demographics—e.g., age, income, ethnicity, education level, etc." [33] (p. 1481).

Furthermore, needs and satisfiers for the society are represented through the social stakeholder layer [33] (p. 1480). Nevertheless, there is no networked visual representation of these two aspects and not necessarily all stakeholders (e.g., partners, suppliers, etc.) of the value creation process are captured.

The BMC extended for infrastructure by Foxon et al. [34] is grounded on a network perspective derived from the following paragraph [34] (p. 4):

"Energy systems are inherently complex, large sociotechnical systems, in that they consist of large number of actors, interacting through networks under changing infrastructures and institutional structures, aiming to provide services including warmth, power and lighting to users" [45].

This networked aspect is not represented in the visualization of the framework. It can be categorized as a component based framework [34] (p. 10). It does not explicitly visualize needs. The concept of satisfiers can be interpreted to be implicitly covered by the extensions for social and environmental value streams and propositions [34] (pp. 1ff). Nevertheless, there is no networked visualization of these aspects provided by the framework.

The Value Triangle (VT) and the VT Business Model Canvas (BMC) provide a framework to represent sustainable business model concepts. These concepts are based on a networked view on sustainable business models, where "[...] firms co-create value within a business ecosystem that includes society and natural environment (see Stubbs and Cocklin [46]") [19] (p. 755). The value triangle serves as a basic structure pointing out various types or values perceived by partners, customers and public and by explicitly pointing out the importance of the interrelation of the business model with society. Furthermore, the VT BMC provides a component based form of representing various aspects of a business model including sustainable aspects. Categorized according to the scheme in Table 1, the VT and VT BM canvas build on a networked business model basis, but do not explicitly visualize this networked perspective. Both framework concepts use a component based type of representation for business model aspects and implicitly represent stakeholder needs and satisfiers with the value proposition structure included.

The Visual Coding Scheme for Sustainable Business Models of Brehmer et al. [35] (p. 4514) use "[... ] a boundary-spanning perspective on business models" to analyze existing sustainable business models. They visually represent business model actors and their value transfer relationships to represent the structure of the business model. Furthermore, they add a visual categorization of the types of value transfers by distinguishing between environmental and social sustainable value exchanges. In regard of the analysis criteria structured in Table 1, their approach can be seen to implicitly and explicitly follow a network perspective. In contrast to the other frameworks analyzed herein, they use a transaction based type of representation. The values exchanged can be interpreted as a way to explicate satisfiers for stakeholder needs, but the approach does not explicate the needs of stakeholders, or the level of fulfillment of needs.

The analysis of existing NBMs in Table 1 indicates the need for a complementing networked modeling tool for sustainable business models to foster the understanding of such complex systems and which is capable of providing a detailed view on the values-based needs and satisfiers of actors. The values and needs layer extending the existing $\mathrm{V}^{2}$ framework proposed in Section 6.2 is targeted to fulfill this need in combination with the other presented layers, which allow various views on complex systems such as sustainable business models. This values and needs layer is not intended to replace, but to complement the listed existing frameworks. While the existing frameworks such as the values-based innovation framework of Breuer and Lüdeke-Freund [17], Breuer and Lüdeke-Freund [24] 
or Bocken et al. [16] are intended to be used in a high-level workshop format to foster early business model innovation phases such as initiation and integration [36] (cf. [47]), the proposed values and needs layer can be used to facilitate follow-up iterations to these initial workshops, which are important to thoroughly analyze initially generated ideas with the aim to provide more detailed information on the envisaged business model needed for further stage gate decisions. The need for further more detailed iterations was also explicitly stated by Breuer and Lüdeke-Freund [24] (p. 25): "The business innovation kit suggests an iterative process. That is, further rounds of refinement could be used to adjust the three VPP business models and the network that emerged during the workshop, for example, to better conform to current laws, regulations and policy frameworks[... ]." Consequently, we refrain from defining entire new workshop formats, but see our proposed framework as an enhancement of existing frameworks to support iterations in the initiation, integration and also implementation phase.

The framework proposed here provides a visualization tool and analysis method that enables a more detailed and networked analysis of socio-techno-economic aspects, which also explicitly covers social aspects and values. Before deepening the toolset to cover these aspects, the concept behind "value" and "values" used in our work need to be defined in more detail. The word "value" has its roots in the Latin word "valere", which can be translated as "something is worth" [48] (p. 39). Instead of only focusing on the monetary value, the term herein "refers to what a person or group of people consider important in life" [49] (p. 2). As described by Breuer and Lüdeke-Freund [24], the concept of "values" is much broader than just pure economic value often denoted as "value". It explicitly includes social and environmental aspects in addition to economic desires of actors. This was also concluded in the description of features of NBMs by Jonker [50] (p. 30) who emphasized the multidimensional nature of values: "Deliberately creating multiple value(s): this is about aiming for a kind of balance among values such as nature, care, attention and money." The notion of values used in this paper follows this wider definition of Breuer and Lüdeke-Freund [24], which is already commonly applied in NBMs.

Modeling of values provides a basis for covering and balancing the social, societal, economic and ecological aspects of a business model. By making these aspects explicit for all actors in a business model, different needs within a value network may be arranged in a viable sense to result in livable and equitable business models [51] (cf. [8]).

The presented method is intended to foster insights into the networked values exchange and needs structures that underlie these business models. The proposed values and needs layer, which complements already published motivation and business dynamics focused layers of the framework, is intended to provide a way to combine conventional business model mindsets with a detailed networked analysis framework to support strongly sustainable and social responsible information system engineering and business model innovation. Existing business model frameworks primarily focus on monetary aspects. However, the integration of moral and ethical aspects may be an additional source of innovation that is currently often neglected [24,52]. Therefore, and due to its increasing importance for business and industry, special focus is placed on integrating ethical values and needs of all actors in a business' ecosystem.

The framework presented in this paper is targeted to support the analysis and planning of information systems with a special emphasis on sustainable business models in a socio-technical system context. It is intended to contribute to the field of business model innovation and business information systems engineering and specifically addresses the point made by Böhmann et al. [15], who defined the integration of social, technological, economic and societal aspects as one of the future challenges for information systems engineering. Ideally, the framework is embedded in a strategic business model innovation process such as the Values-based Innovation Management concept of Breuer and Lüdeke-Freund [24] and Breuer and Lüdeke-Freund [17] or more general in the Dynamic Capabilities concept described by Teece [53]. 


\section{Contribution to Related Fields}

As stated above, the proposed values and needs layer enhancing the $\mathrm{V}^{2}$ framework is intended to incorporate social, technological, economic and societal aspects in complex business models. Therefore, various research strands provide the basis and application areas for the presented new layer and are summarized in this section. Frameworks of the evolving and increasingly relevant research strand of New Business Models aiming at innovating sustainable business models are covered and analyzed in the Introduction. In addition to this application area, the presented framework also contributes to the business information systems engineering and business model innovation community as a tool to foster detailed analysis of evolving or new business model concepts. The strong STS perspective of the values and needs layer explicitly covering social and societal aspects in addition to technical and economic aspects, implicates to also regard research strands such as Value Sensitive Design and Responsible Research and Innovation in this section.

\subsection{Business Information Systems Engineering and Business Model Innovation}

Various frameworks to structure and visualize business models and to guide the related innovation process have been developed in the past two decades. As a means of providing a short overview, we distinguish between the following two aspects:

- Static business model frameworks: These frameworks structure aspects of a business model and describe business model elements in a static way. Frameworks such as [2,54-57] provide important elements or building blocks of business models including the value proposition aspect. The value proposition and how it is realized in a value network is, beside the structure inherent to value distribution for customers including revenue mechanisms and cost structures and the strategic position of the firm, also an important aspect of the more descriptive concept of a business model provided by Chesbrough [1]. Analog to this, various sustainable business model frameworks emerged in recent years. Prominent examples of these frameworks are analyzed in detail in Section 3 and are therefore not explained in more detail here.

- Service and business model innovation process frameworks: These frameworks guide the development process of new products and services and are often combined with the static business model representations or frameworks discussed above. They range from more design oriented frameworks such as the service design thinking process of Stickdorn and Schneider [58], to frameworks targeted at business ventures such as the "Five E" framework consisting of exploration, elaboration, evaluation, experimentation and evolution activities of Breuer [59]. Another important framework specifically targeted at business models with service-dominant logics was provided by Ojasalo et al. [60], who defined four phases: (1) Map and Understand; (2) Forecast and Ideate; (3) Model and Evaluate; and (4) Conceptualize and Influence. In the area of viable and societally acceptable business models, the already aforementioned "Value Mapping Tool" by Bocken et al. [16] is intended to be applied in a workshop setting to facilitate the innovation process of business models from a multi-stakeholder perspective. Beside the analysis of the current value proposition, the tool helps to identify: (1) opportunities for the creation of new values (e.g., potential new services or products); (2) values that are currently missed (e.g., potentials that are not realized by partners); and (3) values that are currently destroyed (e.g., negative social impacts, or pollution of environment) as a result of current value creation practices [16], Furthermore, Breuer and Lüdeke-Freund [17] also provided a structured process for their values-based innovation management approach as a part of their business innovation kit.

\subsection{Sustainable Development and New Business Models}

As described in [51], the concept of sustainable development dates back to 1987 when the United Nations published the Report of the World Commission on Environment and Development: Our Common Future, which is also known as the Brundtland Report [8]. The goal of sustainable 
development is defined in this document as to "[... seek to meet the needs and aspirations of the present without compromising the ability to meet those of the future" [8] (p. 39). The emerging discipline of New Business Models (NBM) is based on concepts of sustainable development as described above and incorporates economic, social, environmental and technical expertise in an interdisciplinary way to create sustainable business models. The underlying research community pursues the goal of developing sustainable and socially acceptable business models often triggered or enabled by new technologies $[10,11]$. As stated by Schaltegger et al. [61] (p. 98) creating a sustainable business case "[... ] requires strategic management to identify, create and strengthen the links between non-monetary social and environmental activities on the one hand and business or economic success on the other hand." In this context, Breuer and Lüdeke-Freund [23] (p. 7) formulated the need that "[...] the formation of successful value networks with viable and sustainable business models requires a synthesis and careful definition of the (normative) values of all network actors, the (multiple) value propositions offered to network stakeholders, and the (economic) value created by and for the involved companies." In this regard, the presented framework provides a concrete toolset to model and analyze these links for each actor in a networked and detailed way on a strategic and operational level. Nevertheless, seen from a global perspective, it needs to be embedded in a general management framework which provides normative structures to facilitate sustainable business model development on a normative level such as the concept provided by Breuer and Lüdeke-Freund [62]. A detailed analysis of NBM innovation frameworks is provided in Section 3.

\subsection{Responsible Research and Innovation, and Value Sensitive Design}

Another important research strand dealing with social, economic and ecological issues in the context of innovation and new technologies is Responsible Research and Innovation (RRI). Both research strands, NBM and RRI, share the common goal of shaping future business and society in a sustainable way. This fact also becomes obvious with the following definition of von Schomberg [12] (p. 63) by describing Responsible Research and Innovation as "[... a transparent, interactive process by which societal actors and innovators become mutually responsive to each other with a view to the (ethical) acceptability, sustainability and societal desirability of the innovation process and its marketable products (in order to allow a proper embedding of scientific and technological advances in our society)".

Another definition provided by the research project KARIM also points out the sustainability aspects of RRI as follows: "Responsible innovation is an approach that consists in taking into account various environmental, social and economic concerns throughout the innovation process with a view to creating value for the society while respecting the environment" [63] (p. 16).

One of the first initiatives for Responsible Research and Innovation was launched by the National Nanotechnology Initiative (NNI), which investigated the applications, risks and opportunities of nanotechnology and tried to anticipate possible future implications on society and the environment. In 2004 and 2005, initiatives to reach out to society and education were launched and also environmental aspects were explicitly considered in these research initiatives $[52,64,65]$.

Whereas the NBM community mainly focuses on business model creation and shaping, the RRI community puts more emphasis on embedding critical thinking in the entire research and development process with the goal of ensuring sustainable and responsible results in the form of new technological advances, products and services. For example, this process was structured by Eden et al. [66] and Stahl et al. [67] referring to Fisher et al. [68] in the following three phases along the research process:

- Upstream activities: These activities can be seen as pre-project activities, which include for example strategic planning of research strategies of funding agencies and also the phase of writing research bids from a researcher's perspective.

- Midstream activities: These activities include actions aimed at ensuring sustainable design during the research or development project.

- Downstream activities: Activities in this phase include actions related to sustainability when the developed services or products reach a maturity level of a marketable product. 
A more engineering and design driven approach to include moral values into technological design was coined by van den Hoven and is termed Value Sensitive Design (VSD) [69,70]. Similar to Breuer and Lüdeke-Freund [24] and Jirotka et al. [52], van den Hoven [71] shared the line of thought that the inclusion of moral values in the research and development process for services, ecosystems and business models may act as a source of innovation rather than a barrier, a process which he described as follows:

"Responsible Innovation is an activity or process which may give rise to previously unknown designs pertaining either to the physical world (e.g., designs of buildings and infrastructure), the conceptual world (e.g., conceptual frameworks, mathematics, logic, theory, software), the institutional world (social and legal institutions, procedures, and organization) or combinations of these, which -when implemented-'expand the set of relevant feasible options regarding solving a set of moral problems' " [71] (p. 82).

In summary, RRI, VSD and NBM are concerned with values related to services and products often enabled by new technologies and their impact on society. All three research strands pursue the goal of innovation that meets the needs of society in a responsible way. However, they differ in their basic orientation and their scientific background. While NBM mainly comes from the field of business model innovation with a business and social background, RRI has a strong social science background and focuses on laying out frameworks to ensure responsible innovation in technology oriented fields of fundamental and application oriented research. The aim of RRI is to embed and ensure a responsible approach to the research and development process, whereas NBM aims to develop and put into practice sustainable business models. The VSD discipline is more engineering driven and puts an emphasis on the technical development process.

\section{Methods}

The presented values and needs layer was iteratively developed based on argumentative-deductive analysis (ADA) and first experiences of its application primarily with information and communication technology (ICT) based information systems were collected.

The Design Science Research paradigm as described by Hevner and Ram [72], Hevner et al. [73] guided the research process, as illustrated in Figure 1. Based on the identified need for a tool that supports the modeling of values in a networked context of a complex system such as a sustainable business model (see Section 3), a modeling concept in the form of the "values and needs layer" was developed. Existing literature and theories served as a knowledge base (see Sections 1-4) for developing the values and needs layer by using ADA, as described in Section 6. Furthermore, the concepts of the values and needs layer were applied in six projects [74-79] with partners in the application areas production, health care and aviation. In four cases, both the tabular and graphical visualization form of the values and needs layer were applied, whereas only the tabular form of representation was used in two cases. In these projects, the values and needs layer in combination with other layers presented in this paper were applied and thereby served as a source of feedback to refine the concept. The application of the values and needs layer in a practical environment supported the development process of the concept proposed. The values and needs layers in these projects were generated by the persons acting as a main driver in the project and were based on personal experiences and insights gained during the conduction of the projects. The results of these practical applications are documented in [74-79]. The case study presented in Section 7 serves as an example to illustrate the practical application. Aspects such as the needs of actors are mainly (as far as possible) drawn from qualitative evaluations, as described in Section 7. Other details such as assessment of the level of met needs are based on personal assumptions by a representative of the project management team. The framework was reported to be helpful to gain more insights into the network of actors, their intentions and motivations to contribute to the value network. Regarding the values and needs layer, for example, a student reported that "with the additional consideration of values and needs of actors, a completely different view on actors can be created. Not only the result, after researching the different needs of actors can be a great 
help for understanding individual decisions, but also the process of generating the values is very helpful "[76]. Despite the insights gained through the application of the values and needs layer in the iterative development process outlined above and the case study presented in Section 7, a comprehensive validation process is required. This process needs to include various groups of users with more cases and is planned for future research activities.

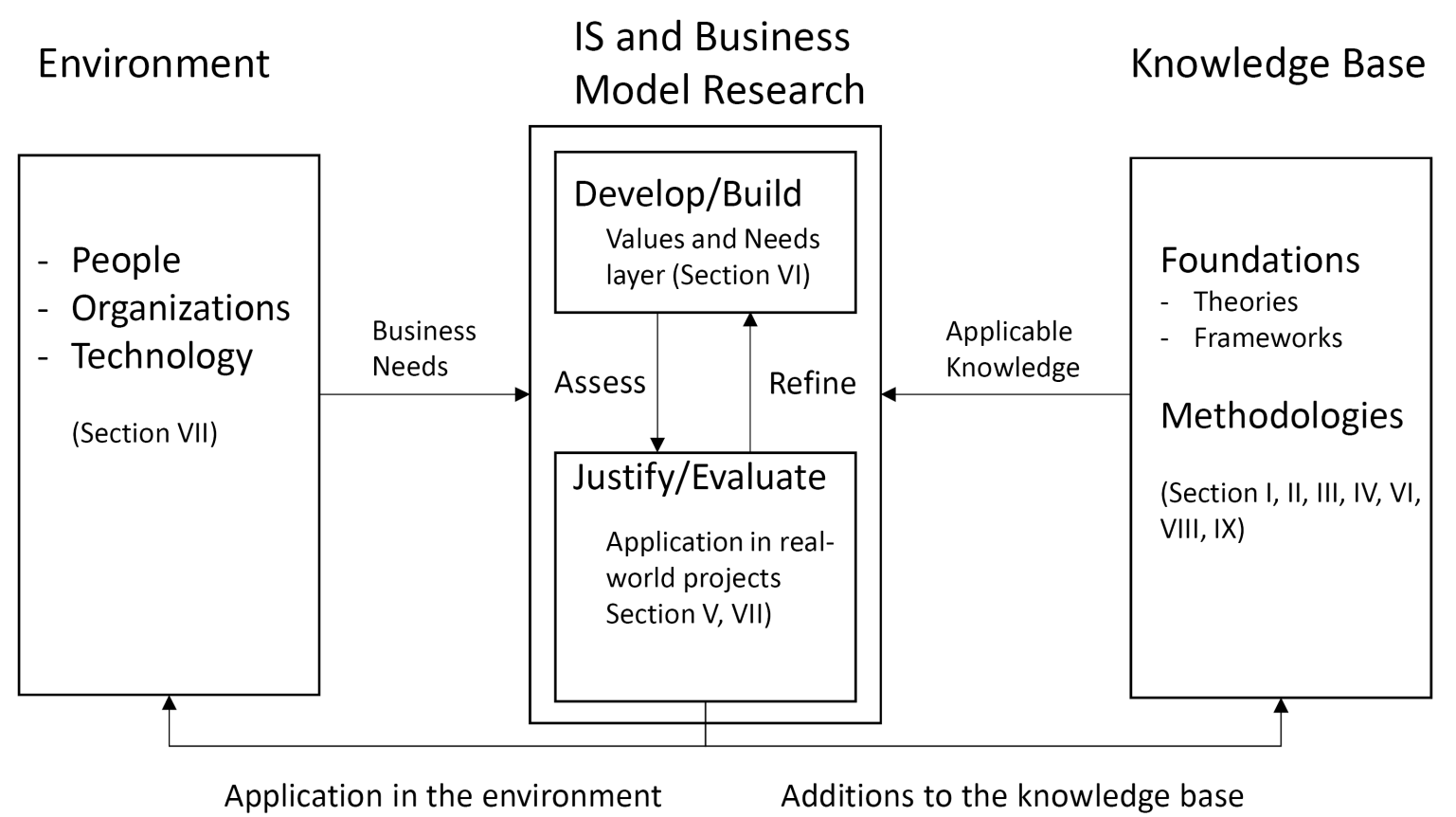

Figure 1. The research method for the development of the proposed values and needs layer structured around the Design Science Research paradigm [72] including the corresponding chapters. (Figure based on Hevner and Ram [72] Copyright (C) 2004, Regents of the University of Minnesota. Reprinted by permission.)

The other layers of the presented framework have been developed incrementally during various research projects over the past few years [20-22]. These layers are also explained in this paper to indicate the advantages of this integrated multi-layered approach by pointing to the aspect that the basic structure of actors has to be created only once and can then be reused for the various aspects of analysis (e.g., legal, business and motivation, values, and needs). Consequently, the enhanced framework can be used to include various perspectives of different stakeholders in one single networked representation.

The framework was initially developed based on non-profit mission-oriented and also profit-oriented service innovation projects. The mission-oriented information services were primarily developed for public safety organizations such as the police. These services were intended to support public safety mission management and other tasks to preserve public safety. The business models behind the mission-based service innovations can be seen as a variant of sustainable business models since they are primarily targeted at societal goals such as preserving public safety. The profit-based service innovation projects mainly dealt with information systems in the automotive industry. The case study introduced below is the first case of a business model concept strongly related to collaboration and alternative social and non-functional values that is analyzed with the presented new layer concept. As a consequence, the proposed framework needs to be further validated within the domain of sustainable business models with more cases. We expect that these cases can potentially show how the framework complements the aforementioned already existing frameworks and also highlight the increasing importance of network effects in sustainable businesses. 


\section{The Layers and Concepts of the Service Analysis and Engineering Framework for New Business Models}

Figure 2 depicts the basic concepts and the various layers of the presented service analysis and engineering framework. The underlying concept of this framework is to "unpack" the broadly accepted BMC with its static and ego-centric view to allow a detailed and connected multi-party analysis of a business model. The consideration of the networked business model instead of simply viewing it as a value chain from an ego-centric view was also emphasized by Jonker [50] (p. 17) who pointed out that "developing a new business model is not just about organising something new within an organisation, but within the entire value network." Value networks are concepts to visualize parties contributing to a business model and the values they exchange between each other. Various types of notations [37-39] exist to illustrate this basic structure. The networked value exchange and resources layer of the presented framework serves as the basis for all other layers. This layer includes all the actors in the business ecosystem and all the value exchanges that take place. Based on this layer, detailed analysis of the other layers can be executed by matter-of-field experts in parallel. In the case of concurrent analysis threads, synchronization points are needed to ensure holistic analysis and design of the business model for the targeted service or product. Strategic business experts and service engineers may discuss these aspects in collaborative sessions. All layers in the framework are described in the following subsections.

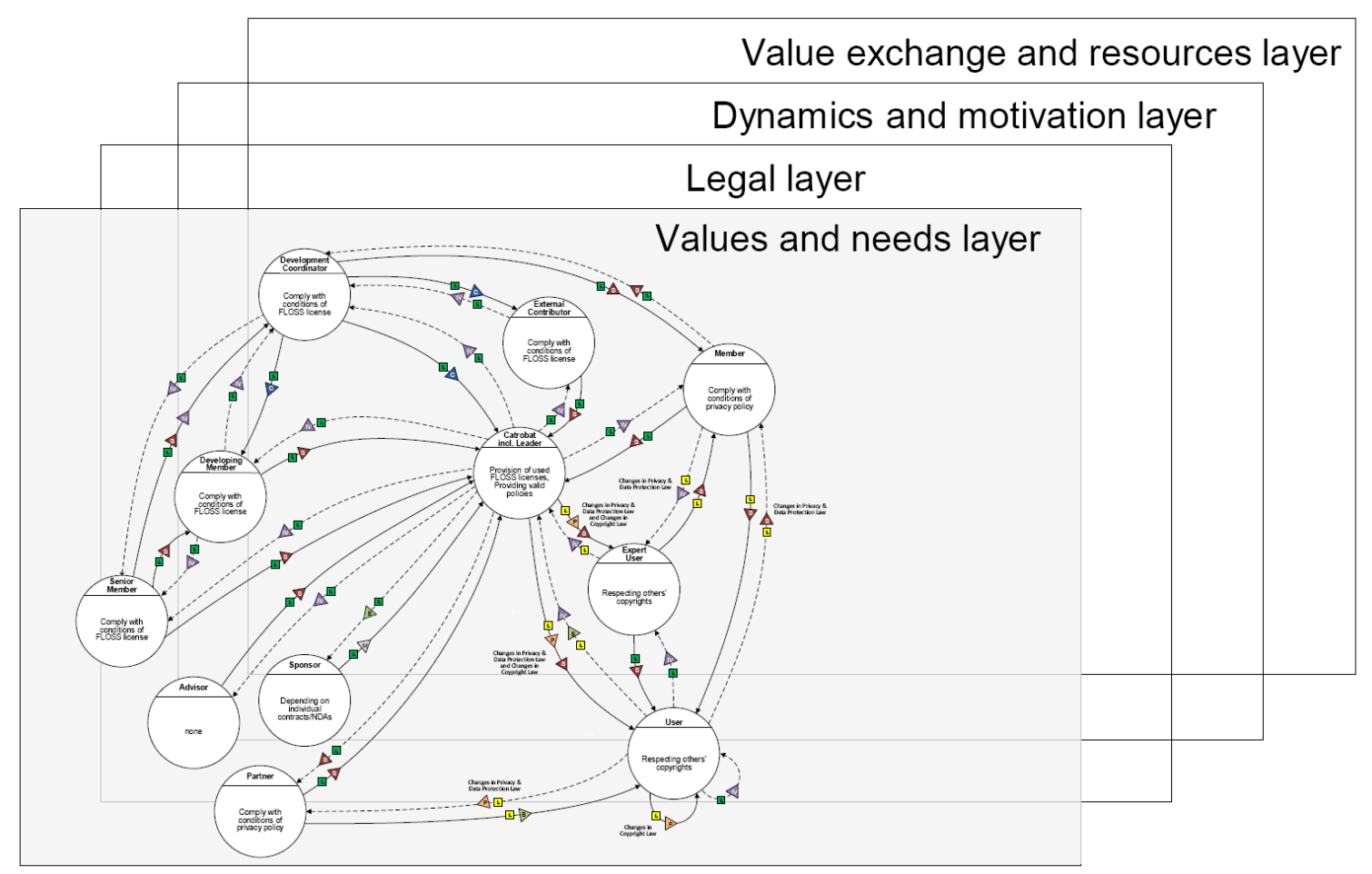

Figure 2. The layer concept of the Service Analysis and Engineering Framework for New Business Models.

The value exchange and resources, legal, and dynamics and motivation layers have already been published previously, but are described briefly to set the new values and needs layer in the context of the entire framework. This also serves to illustrate the benefits of this integrated framework which enables the reuse of basic actors and network structures as a basis for layer-specific viewpoints.

\subsection{Value Exchange and Resources Layer}

The networked value exchange and resources layer (see Figure 3) is a way to represent and analyze actors and the values they exchange between each other from a resource-based perspective [80]. The $\mathrm{V}^{2}$ notation [81] used in the presented framework is based on [39] and enhances it in several ways. The 
basic elements of a value network are its actors and value exchanges. Actors are represented by tripartite circles including the following facts [39]:

- Name: The name or designation of the actor.

- Capabilities: The capabilities are all dynamic aspects such as activities or processes an actor contributes to the value network.

- Assets: The assets are all the tangible and intangible resources (e.g., IT-systems or knowledge) an actor can contribute to the network.

Value exchanges between actors can be represented by directed arcs [39]. Value exchanges into the direction of the end customer are called provision links and are represented by solid lines, whereas dotted lines represent values received by each actor [81]. The values that are exchanged can be categorized into brand, product, information, service and coordination according to Biem and Caswell [39] and also monetary value and intangible value [81]. The resulting value network provides a good overview of the relevant actors and the values exchanged. Based on this network, further aspects of the network can be analyzed within the layers that are described next.
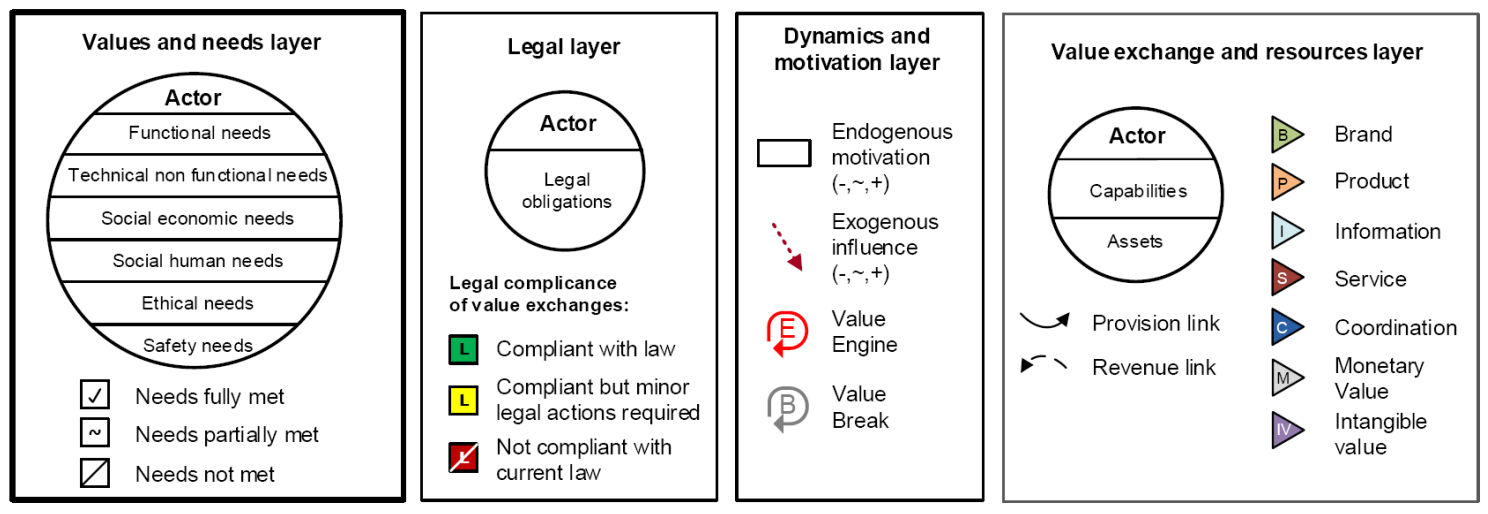

Figure 3. The new values and needs layer (highlighted) and further existing layers of the Service Analysis and Engineering Framework (legal layer based on Vorraber et al. [20], dynamics and motivation based on Vorraber et al. [21], Vorraber and Vössner [81], and value exchange and resources layer based on Biem and Caswell [39], Vorraber and Vössner [81]).

\subsection{Values and Needs Layer}

The enhancement of the values and needs layer (see Figure 3) to the $V^{2}$ value network notation [81] is based on the concept of values, as described above. The presented ethical values network analysis complements the aforementioned frameworks and is supported by Breuer and Lüdeke-Freund [24] who stated that the incorporation of ethical values in business model innovation is underrepresented. It enhances the component-based analysis of values aspects as described by Ojasalo and Ojasalo [26] with network-based visualization and analysis capabilities. The analysis conducted on the networked values and needs layer is intended to allow a more detailed insight on social values of a business ecosystem in a networked way. Therefore, the values and needs layer allows:

- The explicit consideration of social and sustainable aspects during detailed service and value network design.

- The inclusion of a networked and holistic view of the values and needs of all actors in a value network.

This newly introduced layer focuses specifically on different categories of needs (e.g., social economic needs) of the actors within a value network and explicitly includes the social needs of actors, which result from their individual values. The following additional aspects of the actors, as illustrated in Figure 3, should be covered during the information system ecosystem analysis and design: 
- Functional Needs (FN): Needs for a specific functionality to, e.g., support in getting a job or a process done. According to Partsch [82], functional requirements define functional aspects of a system, or what a system or process should be able to accomplish.

- Non-functional needs represent the human side of needs and can further be classified into

- Technical non-functional needs (TNFN): Non-functional needs of actors which need to be fulfilled by the system/service such as handling and design of the user interface and quality requirements to determine the quality of the system (based on Rupp [83]).

- Social economic needs (SEN): Needs of customers (actors) in terms of how customers (actors) want to be perceived by others in economic terms, e.g., bragging and feeling better than others (based on the concept of social jobs in [3]).

- Social human needs (SHN): Needs of customers (actors) in terms of doing good to others or the environment. This aspect covers all three dimensions of a sustainable development including environmental societal and economic aspects, which need to be arranged in a livable, equitable, and viable way to create sustainable business models [51] (based on Environment [8]). This aspect is thus focused more on a person's external environment in a societal, economic and ecological sense.

- Ethical needs (EN): The need of complying with an individual's (actor's) ethics theory [51]. In contrast to the aspect of social human needs, ethical needs are more person centric and focused on a person's ethical theory. For example, the ethical need of privacy is represented by the fact that an employee wants to know and determine what information about himself or herself is communicated to others (e.g., current location of employee in a plant).

- Safety needs (SN): The need for preserving the customer's (actor's) need of safety when using the service (e.g., work and consumer safety).

Analog to the concept described by Gordijn et al. [84] primarily for economic aspects, the level of needs met by satisfiers provided to the actor can be defined as fully, partially or not met (see Figure 3).

The values and needs layer is not intended to replace, but to complement existing frameworks such as the values-based innovation framework of Breuer and Lüdeke-Freund [24] and Breuer and Lüdeke-Freund [17] or the value mapping tool of Bocken et al. [16]. As mentioned above, the overall enhanced framework presented can be used to facilitate follow-up iterations of initial high-level workshops supported by business model innovation tools such as listed in Table 1. Information gained in these high-level workshops can be used as an input for the more detailed iterations suggested for example by the authors of the values-based innovation management approach [24] (p. 25). Data may also be gathered based on literature reviews, shadowing and other context sensitive ways to gain insights into the often tacit intentions of actors in a value network.

\subsection{Legal Layer}

The actors and relations identified in the value exchange and resources layer form a good basis to conduct analysis on the legal layer. As stated above, values exchanged can be tangible or intangible goods such as information, money or services. Not only because of changing and emerging legal regulations (e.g., environmental laws, General Data Protection Regulation (GDRP), etc.), legal compliance of innovations of information systems and the corresponding business models need to be incorporated early in the innovation process. Both the legal obligations of the actors within their organizations and the compliance of the value exchanges need to be assessed by experts. Therefore, organization internal (e.g., GDPR conformity) and also value exchange related compliance can be categorized on a three-point scale as described in Table 2. As stated above, the framework can be used for both existing business models and for planned new business models. This state of realization of the business model also needs to be taken into account during the legal analysis of value exchanges. The enhanced $\mathrm{V}^{2}$ value network notation (see Figure 3 and Table 2) provides a convenient way to model, analyze and communicate 
legal aspects in relation to other important dimensions. The value network with its legal enhancements provides a common shared picture and facilitates communication across interdisciplinary borders of various disciplines such as legal, business or technical experts [20].

Table 2. Compliance levels of value exchanges (extended from Vorraber et al. [20]).

\begin{tabular}{lll}
\hline Symbol & Existing Business Model & Planned Business Model \\
\hline $\begin{array}{l}\text { An “L" covered with } \\
\text { a green rectangle }\end{array}$ & $\begin{array}{l}\text { The value exchange is compliant with legal } \\
\text { regulations }\end{array}$ & $\begin{array}{l}\text { The value exchange is compliant } \\
\text { with legal regulations }\end{array}$ \\
\hline & $\begin{array}{l}\text { The value exchange needs special attention } \\
\text { (e.g., due to anticipated changes of legal } \\
\text { regulations in near future) }\end{array}$ & $\begin{array}{l}\text { the data protection board about } \\
\text { planned data exchanges between } \\
\text { actors) need to be done to be } \\
\text { compliant with existing legal } \\
\text { regulations }\end{array}$ \\
\hline $\begin{array}{l}\text { A crossed out " } \mathrm{L} \text { " } \\
\text { covered with a red } \\
\text { rectangle }\end{array}$ & $\begin{array}{l}\text { The value exchange is not compliant with } \\
\text { existing law. Action required }\end{array}$ & $\begin{array}{l}\text { The planned value exchange is not } \\
\text { compliant with existing legal } \\
\text { regulations and an amendment of } \\
\text { these regulations would be required } \\
\text { to permit the value exchange }\end{array}$ \\
\hline
\end{tabular}

\subsection{Dynamics and Motivation Layer}

As described in [81], actors in a value network may have different incentives and motivations for contributing to a value network. Motivation theory by Vroom [85] and Porter and Lawler [86] conceptualizes internal and external forces, which influence personal and organizational motivation. To analyze these motives and levels of motivation, the following enhancements to Biem and Caswell [39] were defined [81]:

- Endogenous motivation: This aspect describes the level of motivation of persons within an economic entity or actor and is based on the "expectancy theory" of Vroom [85]. The level of motivation is determined by the expected valued outcome for the person when performing the value provision.

- Exogenous influences: This aspect describes the external forces on the actor to perform the expected value generating activities within a value network and is based on Kelman's [87] external influences on a person's compliance and on Porter and Lawler's [86] extrinsic rewards.

As depicted in Figure 3, both concepts can be rated as defensive, neutral and active for each actor [81]. Value exchanges resulting in perceived net benefits for the actors may result in positive value generation and exchange dynamics. Positively perceived value exchange relations in a loop constellation in particular may reinforce the value creation of connected partners and therefore result in "value engines". On the other hand, negatively perceived net benefits may cool down value exchanges between partners and, in case of essential partners and value exchange relations, may therefore put the entire business model at risk [21]. The importance of this overview is supported by Jonker [50] (p. 17) who concluded that "the vision on sustainable business models also gives insight into how the output of several initiatives is taken up by other parties within the value network, enabling great amounts of surplus value. Therefore, it is not so much about the thinking of one party for how to organise sustainably, rather than how the entire value network can participate in it." Furthermore, Bocken et al. [88] (p. 45) pointed out the importance of focusing on the value network and the values created cooperatively, instead of an ego-centric perspective on one company or technology.

Although the creation of the various value network layers may be time-consuming, we think it is necessary to analyze and understand the motivations and reasoning of all participating actors, at least at the presented level of detail. A good overview on all value exchanges and actors is important, especially in the background context of value network dynamics analysis, since only one actor may 
negatively influence the entire value network and may consequently put the entire business model at risk. Other examples such as the case of Google Glass [66] also show that by not meeting ethical or moral values of customers the user acceptance may be negatively influenced and therefore also the entire business model, regardless of the high level of professionalism, the technical implementation and the hype about a new technology. Based on all insights gained through the detailed analysis of the various value network layers and aspects, actors and value exchanges can be rearranged in a more informed manner with the aim of creating sustainable business models.

\section{Case Study}

The benefits of this approach in practice can be shown on a case that was used to define this framework, outlining the different points of view this enhanced layer structure provides compared to the before described $V^{2}$ notation. The Free Open Source Software (FOSS) project "Catrobat" presents a collaborative project driven by a community situated in a complex ecosystem of various actors. As an educational project, Catrobat has a non-profit character following the vision of enabling teenagers to actively create their own apps instead of being merely consumers. The project thus provides various mobile- and web-services free of charge and is backed by volunteer contributors who are helping to bring this vision to life. In addition to the more than 600 contributors who have already been involved in the project, various partners from academia and industry are also providing their support to the project. Many different values are exchanged in a co-creative manner through the charitable ecosystem consisting of actors with different motivations, needs and wants [21]. The collaborative approach of Catrobat's actors already enabled the project to reach more than 750,000 users with its free app "Pocket Code". Thus, it represents an interesting case of a co-creative community, generating a variety of primarily intangible social values by aligning different actors' actions. By collaboratively co-creating multiple values, not following money as currency for value and being accepted by society, this case from the domain of open source software is also highly related to common features that have been identified for sustainable business models [50] (p. 30). However, this ICT enabled innovative project must also ensure its survivability through sufficient financial funding. Therefore, a healthy balance of these monetary values with the intangible values of the volunteer contributors, as well as with the ethical compliance to the project's vision, must be achieved.

The representation of this ecosystem in the existing integrated $\mathrm{V}^{2}$ notation, covering the "Value Exchange and Resources" and "Dynamics and Motivation" layer in one model, has already highlighted benefits for analyzing and managing such co-creative systems that can be found especially in ICT [21]. The application of the enhanced $\mathrm{V}^{2}$ notation with multiple layers eased even further the analysis process for specific stakeholder groups. Although the applied approach in [21] provides a holistic view over the basic system, which is useful for general management and decision making, the analyzing process is eased by the enhanced notation when certain aspects only, e.g., legal concerns or individual actors in relation to the overall system, need to be considered.

Furthermore, the presented framework supports the evaluation of certain actors in more detail, helping to achieve a better understanding of them and to highlight potential gaps that need to be filled (e.g., unmet needs) in the network. Whereas the overall value network notation of $\mathrm{V}^{2}$, without enhancements, helps in providing a quick holistic view of the system, the presented layer-based approach is supposed to zoom in on actor level, as shown in Figure 4, to gain a high-level understanding that might be necessary for management and strategic decisions. The framework has been initially created in an expert workshop, as suggested above. Within this workshop of different long-term contributors of the project, each having a different background, the actors of the ecosystem were identified before drafting the network. By then evaluating the needs of each actor, as described in the networked values and needs layer section, and afterwards putting it in connection to the received values and relationships to other actors, the understanding of the if and how these needs are met can be easily created, visualized and communicated. Within this case, especially the motivational aspects and needs were further backed by a qualitative study in the scope of surveys [89], helping to obtain 
an even more detailed understanding of them. In following iterations, in a smaller setting, the initial network was extended to the presented layers, creating a holistic picture of the ecosystem. As the example of Catrobat shows, this approach enables a focus on individual actors in a precise matter by also putting it into context of the value network within one single notation. To illustrate this benefit of the multi-layer network approach, we zoom in to actor level and stress the insights that can be gained in practice.

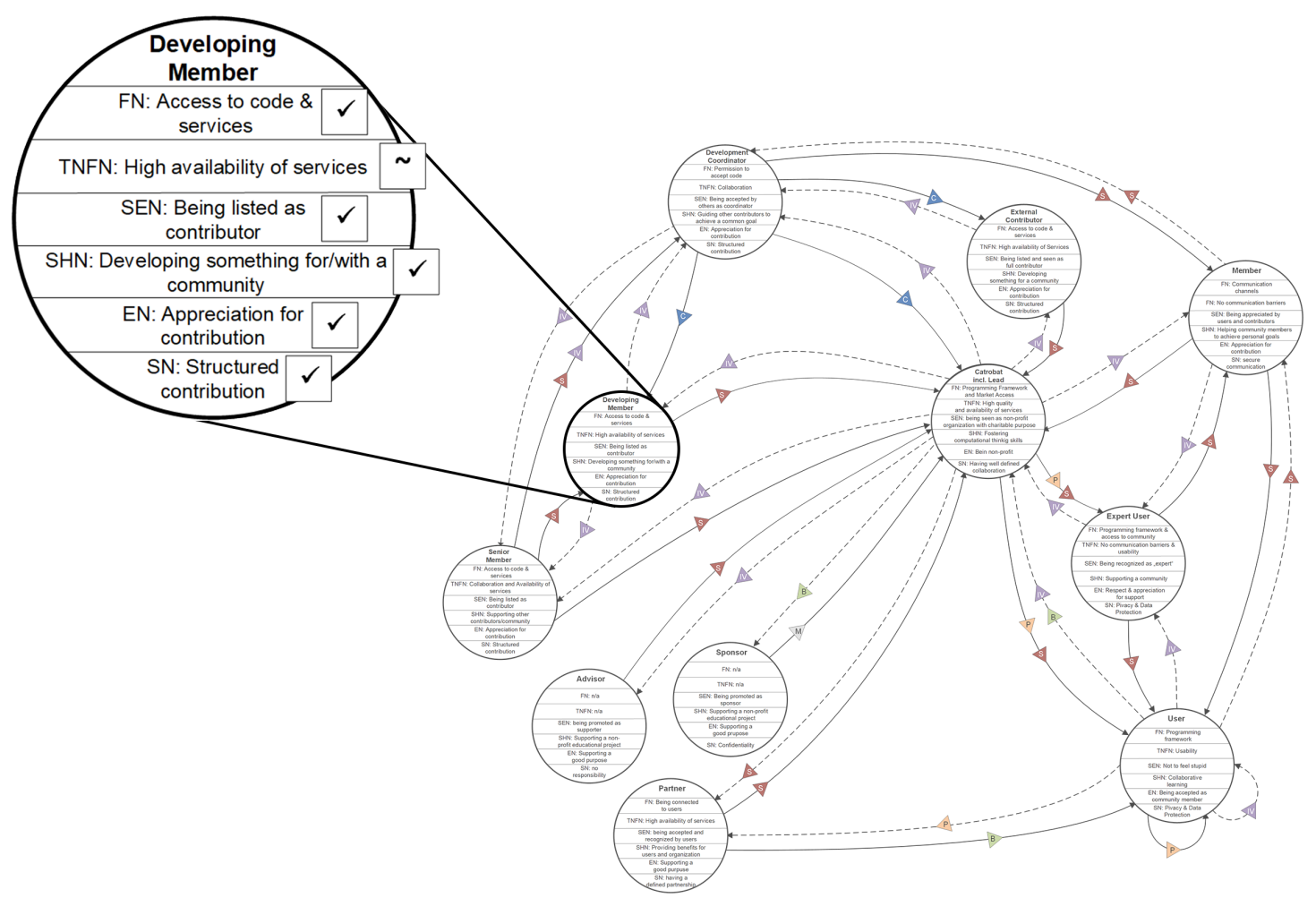

Figure 4. Zooming into the developing members' individual needs within the networked values and needs layer.

As already lined out in previous research, students, the main contributors of Catrobat, participate in this project for various personal reasons such as supporting the project's goal, seeing it as reference for their later career, or being part of a community [89]. These valuable insights of specific actors can be represented in a very detailed level depending on the organizations' purpose of analysis, as illustrated in Figure 4. Especially needs and values that are met by received intangible values, e.g., in this case related to co-creating value with others or doing good for a community, can be represented in this layer and its different perspectives provided by the categorization. As an example, the developers have a social human need (SHN) to develop something for/with a community, which is directly related to the project's vision. However, the identified developers' need to have a reference for their later career is directly linked to the illustrated social economic need (SEN) to be listed, so being visible and recognized, as a contributor of the project in return, ensuring that the actor may gain an intangible net-benefit for their contribution. This representation of specific needs also fosters the understanding of NBMs that are often based on intangible and social values transferred in and co-created by open communities. As Jonker [50] (p. 21) described it, collaboration and exchanging tangible as well as intangible values are important aspects for sustainable business models. Lining out these values and needs, as it was done in this case study, helps to better understand the personal motivation of contributing actors to participate in the ecosystem, as well as how their (social) needs can be met in return to keep them in the long term. The identified motivations, as done for this specific case in [89], can be put into the context of the different categories and be seen in relation to the whole 
ecosystem. In this case, the enhanced visual layer representation also eases the communication process and documents the outcomes over time, which has already been outlined as beneficial in analyzing and managing complex ecosystems [21]. This holistic understanding provided by the networked values and needs layer can be even further beneficial if detailed knowledge of a variety of different actors in a community is needed to manage them into a common direction, which, as in this case, is not necessarily primarily based on monetary profit or tangible values.

One example of how this layer-based viewpoint further proved to be beneficial is the legal layer of Catrobat, as illustrated in Figure 5. Whereas the connection between contributing actors is well defined by formulated open source software licenses and the joint work with partners on an individual basis, e.g., contracts or NDAs, the relationship to the end-users needs special attention. Especially currently ongoing and proposed changes in privacy/data protection and copyright law need to be considered for these specific connections. Adaptations to the end-users' terms of use and privacy policy might be needed in the foreseeable future and will therefore need to be prepared adequately. Especially the need for privacy, which is ensured through legal regulations, is directly related to social needs of the users, who expect their data to be safe, resulting in a want that needs to get represented on that layer. This shows that these layers may influence each other, making it important to combine them in one toolkit and visualize them for everyone involved in the decision making process.

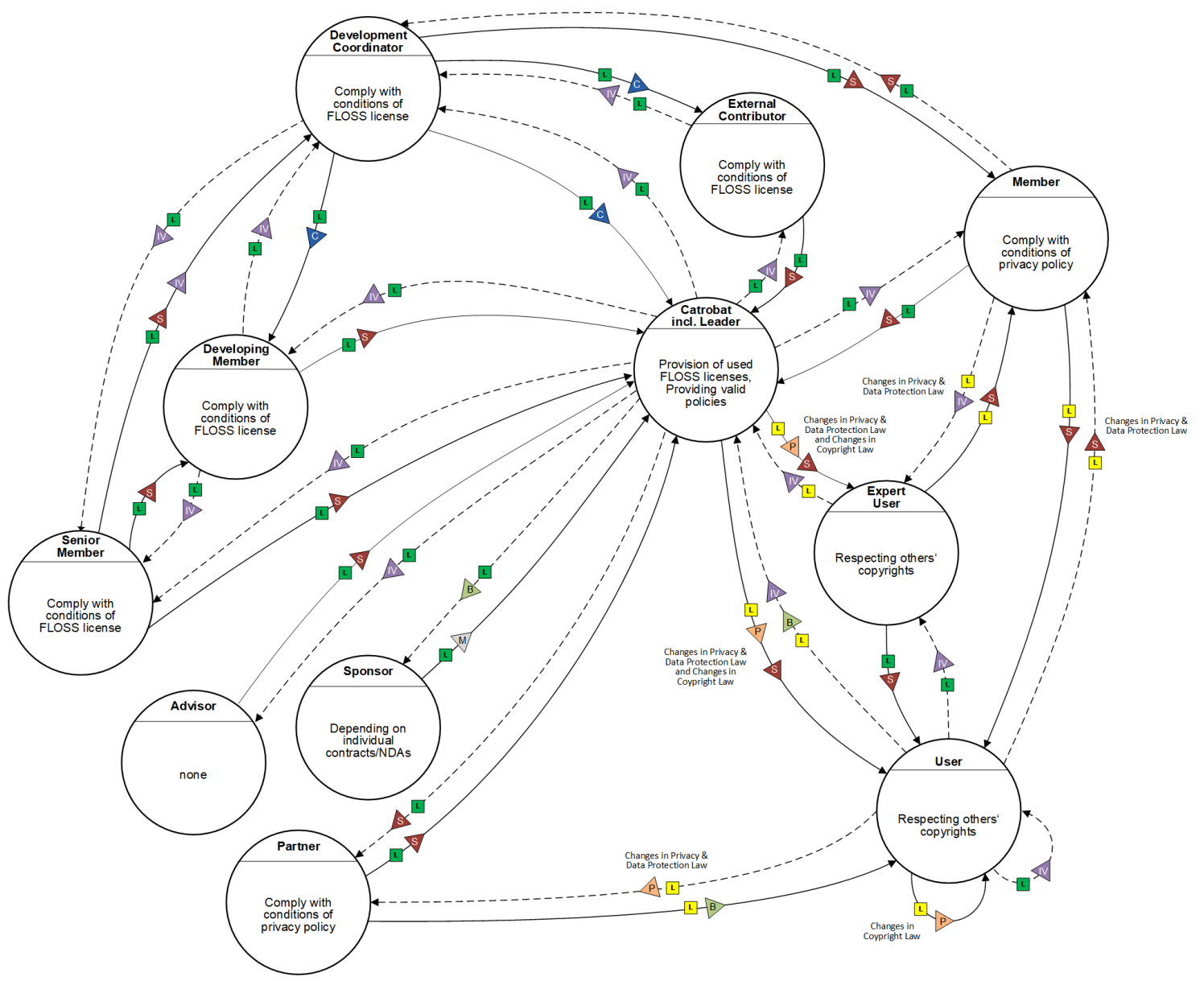

Figure 5. The legal and value exchange layer of the Catrobat project.

\section{Discussion}

In this paper, we present an enhanced multi-layer framework that is intended to complement existing sustainable business model frameworks by providing a networked visualization method for values-based innovation, as outlined in Section 3. Based on the $\mathrm{V}^{2}$ notation, it incorporates important 
key concepts of information system and business model innovation. It is aimed to facilitate the innovation process by providing a toolset to analyze and arrange actors and value exchanges of a business model that meets the desired goals of social and environmental acceptability while preserving economic viability. The main key concepts underlying this framework are:

- Approaching business models with a network-focused rather than an ego-centric view, as highlighted by Bocken et al. [16] (p. 488) and Breuer and Lüdeke-Freund [24]. Based on this, the networked approach in the presented framework facilitates the quest for a balanced optimum on a network level rather than a local optimum for single actors resulting in possible negative effects on the value dynamics perspective. Our merit here is to provide a multi-layered toolbox that facilitates the modeling, analysis and communication of multiple aspects on the detailed level of value networks.

- Integration of values in an extended sense including social, ecological and technical aspects in addition to economic aspects into service and business model innovation. This aspect is built on various pillars from different research strands such as Responsible Research and Innovation [52], Value Sensitive Design [69] and New Business Models [24]. Our merit here is the integration of these aspects on a detailed, but from our point of view necessary fine grained level in the form of the multi-layered analysis and design toolbox presented above.

The framework presented here is not intended to serve as another abstract information service and business model innovation framework, but is intended rather to facilitate a more detailed and multi-faceted analysis and view on the networked business model. In this sense, it can be seen as a framework complementing and refining the values-based framework of Breuer and Lüdeke-Freund [24] and Bocken et al. [16] by providing a toolset to specify and analyze the needs and values of all actors in a networked way and to provide insights into the values exchanged and value dynamics of these relations. This goes along with Breuer and Lüdeke-Freund [24] (p. 16) who expressed the need for "[...] a synthesis and careful definition of not only the values and normative orientations of all network stakeholder, but also the multiple value propositions offered to them and the valuable outcomes created with and for them" in the context of viable and societally acceptable business model creation. Our framework presents an approach to foster the ideas of values-based network and business model innovation [24] and provides a toolset to follow a hybrid way to create product/service innovation and track its consequences on business model innovation. We do this by explicitly modeling and analyzing value propositions, values, legal aspects and financial flows in a consistent manner. Although the practicability of this fine grained analysis on the value network level may be discussed as criticized by Bocken et al. [16], we think it is necessary to analyze and understand the motivations and reasoning of all participating actors at least in the level of detail as presented. Especially from the background of value network dynamics analysis, a detailed analysis is important, since only one actor may negatively influence the entire value network and consequently may inhibit value creation of the entire business model [21]. Furthermore, the detailed modeling may also facilitate the process of resolving contradicting values-based goals of network members by first of all making them explicit and by providing a common picture to collaboratively discuss possible solutions. In this sense, it supports the values-based framework of Breuer and Lüdeke-Freund [24] (p. 30) "[... to overcome barriers to the implementation of sustainability-oriented innovations" by explicitly modeling all actors needs and values. The presented framework is also intended to facilitate analysis and communication in the interdisciplinary teams of legal, technical, economic and social experts. It is important to condense the often comprehensive expertise from legal experts into practical decisions, especially from the point of view of technicians and economists. In a larger and research strand overarching context, the presented framework can be seen as another brick in the puzzle to support Responsible Research and Innovation and the creation of NBM by providing a detailed analysis and design toolset for new and often ICT-enabled services or products. The proposed values and needs layer can be iteratively applied during all phases of RRI activities (upstream, midstream, and downstream) defined by Eden et al. [66] and Stahl et al. [67] referring to Fisher et al. [68] to analyze the needs of various 
actors and to arrange value exchanges to ensure sustainability in all phases. Nevertheless, it is especially suited for midstream and downstream activities, where either new business models for information systems can be designed or existing business models can be innovated. The presented tool is not primarily intended as a high level RRI framework. Rather it seeks to complement existing RRI frameworks and to facilitate the planning and innovation process of services and products with a toolset to visualize and communicate multiple-stakeholder and actor perspectives and to arrange ecosystems of business models in a sustainable way. The proposed values and needs layer enhancing the existing $\mathrm{V}^{2}$ framework incorporates the central values aspects of research strands NBM, RRI and VSD and is intended to provide a tool that can be used in the course of a responsible innovation process. It is applicable in all three presented research strands by providing a systematic approach to analyze and shape a network of value exchanges that fulfills the needs and values of all the actors involved in a business model. The insights gained with this toolset can be used for making better informed decisions in the technical realization of a service (VSD), support critical reflections, especially for the people and purpose dimensions of the 4Ps framework [67] (RRI) and can be used for detailed analysis and design of networked sustainable business models (NBM).

Bringing together all stakeholders of a business model venture to elaborate business model ideas and jointly overcome possible barriers as proposed by Breuer and Lüdeke-Freund [24] is a great approach for developing new business models or solving wicked problems. Nevertheless, it is often extremely difficult to bring all actors of a planned or existing value network to one table. Our framework helps to systematically create a big picture and analyze the value network based on data collected through workshops either with all the stakeholders or based on individual sessions with selected stakeholders.

\section{Conclusion and Outlook}

We proposed a new layer in addition to an existing analysis framework ( $\mathrm{V}^{2}$ notation) that is intended to complement existing high-level business model innovation frameworks with a toolset to understand underlying networked ecosystems from a multi-actor perspective according to various essential aspects of business models. A multi-layered and multi-actor analysis approach is used to reveal relations, interdependencies and dynamics between participating entities in a business network. A special focus is placed on the different values and needs of actors to support the development of viable and societally acceptable business models. After introducing the new layer and conceptualizing the various existing analysis layers, a large-scale open source project served as a case to present the application of the framework and provide first impressions of the possible insights that can be gained with the framework. In the course of laying out the theoretical foundation of our framework, we provided an overview on the research areas of strongly sustainable or New Business Models, Responsible Research and Innovation and Value Sensitive Design. By doing so, we identified interesting cross-community links between these research strands and summarized their differences.

Experiences gained from the application of the presented framework for information system engineering showed that the framework may generate important insights to guide service and product innovation and consequently business model innovation processes. As indicated in the analysis of existing sustainable business model innovation frameworks, the framework adds to existing literature by complementing these high-level frameworks with a toolset aimed to support more detailed ecosystem analysis iterations following initial business model innovation activities (e.g., large stakeholder workshops).

Recently, a dedicated web-based tool to facilitate the creation of the graphs and entering the required data has been developed [90]. The tool provides all visual elements of the framework in a predefined and interactive way that allows a drag and drop based creation of the graphs. Furthermore, the tool provides an internal data model that can be used for simulation studies. It is planned to use this tool for the future validation activities required as indicated above and to make the tool publicly available to broaden its application. 
Author Contributions: Conceptualization, W.V. and M.M.; research design, W.V. and M.M.; literature review, W.V. and M.M.; writing_-original draft W.V. and M.M.; and writing—review and editing, W.V. and M.M.

Funding: This research received no external funding.

Acknowledgments: Open Access Funding by the Graz University of Technology.

Conflicts of Interest: The authors declare no conflict of interest.

\section{References}

1. Chesbrough, H. Business Model Innovation: Opportunities and Barriers. Long Range Plan. 2010, 43, 354-363. [CrossRef]

2. Osterwalder, A.; Pigneur, Y. Business Model Generation: A Handbook for Visionaries, Game Changers, and Challengers; John Wiley \& Sons: Hoboken, NJ, USA, 2010.

3. Osterwalder, A.; Pigneur, Y.; Bernarda, G.; Smith, A. Value Proposition Design: How to Create Products and Services Customers Want; John Wiley \& Sons: Hoboken, NJ, USA, 2014.

4. Wirtz, B.W.; Pistoia, A.; Ullrich, S.; Göttel, V. Business models: Origin, development and future research perspectives. Long Range Plan. 2016, 49, 36-54. [CrossRef]

5. Trist, E. The Evolution of Socio-Technical Systems; Occasional paper No.2 June 1981; Ontario Quality of Working Life Centre: Toronto, ON, Canada, 1981.

6. Mumford, E. The story of socio-technical design: Reflections on its successes, failures and potential. Inf. Syst. J. 2006, 16, 317-342. [CrossRef]

7. Carayon, P.; Hancock, P.; Leveson, N.; Noy, I.; Sznelwar, L.; Hootegem, G.V. Advancing a sociotechnical systems approach to workplace safety-developing the conceptual framework. Ergonomics 2015, 58, 548-564. [CrossRef]

8. United Nations World Commission on Environment and Development Report of the World Commission on Environment and Development: Our Common Future; Technical report; United Nations: New York, NY, USA, 1987.

9. Upward, A.; Jones, P. An ontology for strongly sustainable business models: Defining an enterprise framework compatible with natural and social science. Organ. Environ. 2016, 29, 97-123. [CrossRef]

10. Dentchev, N.; Baumgartner, R.; Dieleman, H.; Jóhannsdóttir, L.; Jonker, J.; Nyberg, T.; Rauter, R.; Rosano, M.; Snihur, Y.; Tang, X.; et al. Embracing the variety of sustainable business models: Social entrepreneurship, corporate intrapreneurship, creativity, innovation, and other approaches to sustainability challenges. J. Clean. Prod. 2016. [CrossRef]

11. Rauter, R.; Jonker, J.; Baumgartner, R.J. Going one's own way: Drivers in developing business models for sustainability. J. Clean. Prod. 2017, 140, 144-154. [CrossRef]

12. von Schomberg, R. A Vision of Responsible Research and Innovation. In Responsible Innovation; John Wiley \& Sons, Ltd.: Hoboken, NJ, USA, 2013; Chapter 3, pp. 51-74. [CrossRef]

13. Tsujimoto, M.; Kajikawa, Y.; Tomita, J.; Matsumoto, Y. A review of the ecosystem concept - Towards coherent ecosystem design. Technol. Forecast. Soc. Chang. 2018, 136, 49 - 58. [CrossRef]

14. Max-Neef, M.; Dlizalde, A.; Hopenhayn, M. Human Scale Development: Conception, Application and Further Reflections; Apex Press: New York, NY, USA, 1991.

15. Böhmann, T.; Leimeister, J.M.; Möslein, K. The New Fontiers of Service Systems Engineering. Bus. Inf. Syst. Eng. 2018, 60, 373-375. [CrossRef]

16. Bocken, N.; Short, S.; Rana, P.; Evans, S. A value mapping tool for sustainable business modelling. Corp. Governance Int. J. Bus. Soc. 2013, 13, 482-497. [CrossRef]

17. Breuer, H.; Lüdeke-Freund, F. Values-Based Innovation Management: Innovating by What We Care about; Macmillan International Higher Education: London, UK, 2017.

18. Massa, L.; Gianluigi, V.; Tucci, C. Business models and complexity. J. Bus. Model. 2018, 6, 59-71.

19. Biloslavo, R.; Bagnoli, C.; Edgar, D. An eco-critical perspective on business models: The value triangle as an approach to closing the sustainability gap. J. Clean. Prod. 2018, 174, 746-762. [CrossRef]

20. Vorraber, W.; Lichtenegger, G.; Brugger, J.; Gojmerac, I.; Egly, M.; Panzenböck, K.; Exner, E.; Aschbacher, H.; Christian, M.; Voessner, S. Designing Information Systems to Facilitate Civil-Military Cooperation in Disaster Management. Int. J. Distrib. Syst. Technol. (IJDST) 2016, 7, 22-40. [CrossRef] 
21. Vorraber, W.; Müller, M.; Voessner, S.; Slany, W. Analyzing and Managing Complex Software Ecosystems: A Framework to Understand Value in Information Systems. IEEE Softw. 2018, 36, 55-60. [CrossRef]

22. Lichtenegger, G.; Vorraber, W.; Gojmerac, I.; Sporer, A.; Brugger, J.; Exner, E.; Aschbacher, H.; Christian, M.; Voessner, S. Identification of information gaps in civil-military cooperation in disaster management. In Proceedings of the 2nd International Conference on Information and Communication Technologies for Disaster Management (ICT-DM), Rennes, France, 30 November-2 December 2015. [CrossRef]

23. Breuer, H.; Lüdeke-Freund, F. Normative Innovation for Sustainable Business Models in Value Networks. In Proceedings of the XXV ISPIM Conference-Innovation for Sustainable Economy and Society, Dublin, Ireland, 8-11 June 2014; pp. 120-148. [CrossRef]

24. Breuer, H.; Lüdeke-Freund, F. Values-based network and business model innovation. Int. J. Innov. Manag. 2017, 21, 1750028. [CrossRef]

25. Massa, L.; Tucci, C.L. Business model innovation. Oxf. Handb. Innov. Manag. 2013, 20, 420-441.

26. Ojasalo, K.; Ojasalo, J. Adapting business model thinking to service logic: An empirical study on developing a service design tool. In The Nordic School-Service Marketing and Management for the Future; Gummerus, J., Von Koskull, C., Eds.; CERS, Hanken School of Economics: Helsinki, Finland, 2015; pp. 309-333.

27. Ehrenfeld, J.R. Colorless Green Ideas Sleep Furiously: Is the Emergence of "Sustainable" Practices Meaningful? Reflect. Sol J. 2000, 1, 34-47. [CrossRef]

28. Willard, B.; Kendall, G.; Leung, P.; Park, C.; Rich, M.; Upward, A. Future Fit Business Benchmark; The Natural Step Canada and 3D Investment Foundation: London, UK, 2014.

29. Breuer, H.; Fichter, K.; Lüdeke-Freund, F.; Tiemann, I. Sustainability-oriented business model development: Principles, criteria, and tools. Int. J. Entrep. Ventur. 2018, 10, 256-286. [CrossRef]

30. Glinik, M.; Vorbach, S. Sustainable Business Models. In Industrial Life Cycle Management-Sustainability Management for Industries 8; Biedermann, H., Vorbach, S., Posch, W., Eds.; Rainer Hampp Verlag: Augsburg/München, Germany, 2019; pp. 11-23.

31. Jones, P.; Upward, A. Caring for the future: The systemic design of flourishing enterprises. In Proceedings of the RSD3, Third Symposium of Relating Systems Thinking to Design, Oslo, Norway, 15-17 October 2014; pp. 1-8.

32. Tiemann, I.; Fichter, K. Developing Business Models with the Sustainable Business Canvas: Manual for Conducting Workshops; Carl von Ossietzky University of Oldenburg: Oldenburg/Berlin, Germany, 2016.

33. Joyce, A.; Paquin, R.L. The triple layered business model canvas: A tool to design more sustainable business models. J. Clean. Prod. 2016, 135, 1474-1486. [CrossRef]

34. Foxon, T.J.; Bale, C.S.; Busch, J.; Bush, R.; Hall, S.; Roelich, K. Low carbon infrastructure investment: Extending business models for sustainability. Infrastruct. Complex. 2015, 2, 4. [CrossRef]

35. Brehmer, M.; Podoynitsyna, K.; Langerak, F. Sustainable business models as boundary-spanning systems of value transfers. J. Clean. Prod. 2018, 172, 4514 - 4531. [CrossRef]

36. Täuscher, K.; Abdelkafi, N. Visual tools for business model innovation: Recommendations from a cognitive perspective. Creat. Innov. Manag. 2017, 26, 160-174. [CrossRef]

37. Gordijn, J.; Akkermans, H.; van Vliet, H. Business Modelling Is Not Process Modelling. In Conceptual Modeling for E-Business and the Web; Springer: Berlin/Heidelberg, Germany, 2000; pp. 40-51. [CrossRef]

38. Allee, V. Value-creating networks: Organizational issues and challenges. Learn. Organ. 2009, 16, 427-442. [CrossRef]

39. Biem, A.; Caswell, N. A Value Network Model for Strategic Analysis. In Proceedings of the 41st Annual Hawaii International Conference on System Sciences, Waikoloa, HI, USA, 7-10 January 2008. [CrossRef]

40. Peppard, J.; Rylander, A. From value chain to value network: Insights for mobile operators. Eur. Manag. J. 2006, 24, 128-141. [CrossRef]

41. Larkin, J.H.; Simon, H.A. Why a diagram is (sometimes) worth ten thousand words. Cogn. Sci. 1987, 11, 65-100. [CrossRef]

42. Tversky, B. Visualizing Thought. Top. Cogn. Sci. 2011, 3, 499-535. [CrossRef]

43. Hegarty, M. The cognitive science of visual-spatial displays: Implications for design. Top. Cogn. Sci. 2011, 3, 446-474. [CrossRef]

44. Zhang, K. Using visual languages in management. J. Vis. Lang. Comput. 2012, 23, 340-343. [CrossRef]

45. Bale, C.S.; Varga, L.; Foxon, T.J. Energy and complexity: New ways forward. Appl. Energy 2015, 138, 150-159. [CrossRef] 
46. Stubbs, W.; Cocklin, C. Conceptualizing a “Sustainability Business Model”. Organ. Environ. 2008, 21, $103-127$. [CrossRef]

47. Frankenberger, K.; Weiblen, T.; Csik, M.; Gassmann, O. The 4I-framework of business model innovation: A structured view on process phases and challenges. Int. J. Prod. Dev. 2013, 18, 249-273. [CrossRef]

48. Spiekermann, S. Ethical IT Innovation; Taylor \& Francis: Boca Raton, FL, USA, 2015.

49. Friedman, B.; Kahn, P.H.; Borning, A.; Huldtgren, A. Value Sensitive Design and Information Systems. In Early Engagement and New Technologies: Opening Up the Laboratory; Springer: Amsterdam, The Netherlands, 2013; pp. 55-95. [CrossRef]

50. Jonker, J. New Business Models: A Explorative Study of Changing Transactions Creating Multiple Values; Jab Management Consultants bv: Doetinchem, The Netherlands, 2012.

51. Pavie, X.; Scholten, V.; Carthy, D. Responsible Innovation-From Concept to Practice; World Scientific Publishing Company: Singapore, 2014.

52. Jirotka, M.; Grimpe, B.; Stahl, B.; Eden, G.; Hartswood, M. Responsible research and innovation in the digital age. Commun. ACM 2017, 60, 62-68. [CrossRef]

53. Teece, D.J. Explicating dynamic capabilities: The nature and microfoundations of (sustainable) enterprise performance. Strateg. Manag. J. 2007, 28, 1319-1350. [CrossRef]

54. Gjerde, I.; Eskedal, T.; Venturin, R. BIZTEKON A framework for business modelling and techno-economic analysis. In Proceedings of the 9th International Conference on Telecommunications, Zagreb, Croatia, 13-15 June 2007.

55. Bouwman, H.; Vos, J.D.; Haaker, T. Mobile Service Innovation and Business Models; Springer: Berlin/Heidelberg, Germany, 2008.

56. Furseth, P.I.; Cuthbertson, R. The service innovation triangle: A tool for exploring value creation through service innovation. Int. J. Technol. Mark. 2013, 8, 159-176. [CrossRef]

57. Breuer, H.; Ketabdar, H. User-Driven Business Model Innovation-New Formats and Methods in Business Modeling and Interaction Design, and the Case of Magitact. In Proceedings of the IADIS International Conference on E-Society, Berlin, Germany 10-13 March 2012; pp. 211-218.

58. Stickdorn, M.; Schneider, J. This Is Service Design Thinking: Basics, Tools, Cases; Number 4; BIS Publishers BV: Amsterdam, The Netherlands, 2014.

59. Breuer, H. Lean venturing: Learning to create new business THROUGH Exploration, elaboration, evaluation, experimentation, and evolution. Int. J. Innov. Manag. 2013, 17, 1340013. [CrossRef]

60. Ojasalo, K.; Koskelo, M.; Nousiainen, A.K. Foresight and Service Design Boosting Dynamic Capabilities in Service Innovation. In The Handbook of Service Innovation; Springer: London, UK, 2015; pp. 193-212. [CrossRef]

61. Schaltegger, S.; Freund, F.L.; Hansen, E.G. Business cases for sustainability: The role of business model innovation for corporate sustainability. Int. J. Innov. Sustain. Dev. 2012, 6, 95. [CrossRef]

62. Breuer, H.; Lüdeke-Freund, F. Values-Based Innovation Framework-Innovating by What We Care About. In Proceedings of the XXVI ISPIM Conference, Budapest, Hungary, 14-17 June 2015.

63. Bau, F.; Forster, M. The KARIM Innovation Map \& the Network Typology; Technical report; HTW Chur: Chur, Switzerland, 2014.

64. Roco, M.C. The long view of nanotechnology development: The National Nanotechnology Initiative at 10 years. J. Nanoparticle Res. 2011, 13, 427-445. [CrossRef]

65. Fisher, E.; Rip, A. Responsible Innovation: Multi-Level Dynamics and Soft Intervention Practices. In Responsible Innovation; John Wiley \& Sons, Ltd.: Hoboken, NJ, USA, 2013; pp. 165-183. [CrossRef]

66. Eden, G.; Jirotka, M.; Stahl, B. Responsible research and innovation: Critical reflection into the potential social consequences of ICT. In Proceedings of the IEEE 7th International Conference on Research Challenges in Information Science (RCIS), Paris, France, 29-31 May 2013. [CrossRef]

67. Stahl, B.; Jirotka, M.; Eden, G. Responsible Research and Innovation in Information And Communication Technology; John Wiley \& Sons, Ltd.: Hoboken, NJ, USA, 2013; pp. 199-218. [CrossRef]

68. Fisher, E.; Mahajan, R.L.; Mitcham, C. Midstream Modulation of Technology: Governance From Within. Bull. Sci. Technol. Soc. 2006, 26, 485-496. [CrossRef]

69. van den Hoven, J. ICT and Value Sensitive Design. The Information Society: Innovation, Legitimacy, Ethics and Democracy In Honor of Professor Jacques Berleur s.j.; Goujon, P., Lavelle, S., Duquenoy, P., Kimppa, K., Laurent, V., Eds.; Springer: Boston, MA, USA, 2007; pp. 67-72. 
70. den Hoven, J.V.; Lokhorst, G.J.; de Poel, I.V. Engineering and the Problem of Moral Overload. Sci. Eng. Ethics 2011, 18, 143-155. [CrossRef]

71. van den Hoven, J. Value Sensitive Design and Responsible Innovation. In Responsible Innovation; John Wiley \& Sons, Ltd.: Hoboken, NJ, USA, 2013; pp. 75-83. [CrossRef]

72. Hevner, A.R., Alan, R.; March, S.T.; Ram, S. Design Science in Information Systems Research. MIS Q. 2004, 28, 75-105. [CrossRef]

73. Hevner, A.; vom Brocke, J.; Maedche, A. Roles of Digital Innovation in Design Science Research. Bus. Inf. Syst. Eng. 2018. [CrossRef]

74. Aluani, C. Utilizing Augmented Reality Based Guiding Techniques in Service Design. Master's Thesis, Graz University of Technology, Graz, Austria, 2018.

75. Eder, L. Designing Indoor and Outdoor Localization Information Services in Production Environment. Master's Thesis, Graz University of Technology, Graz, Austria, 2016.

76. Frohmann, P. Utilization of Augmented Reality in Aviation-Assisting Small Aircraft Pilots in Approaching and Landing. Master's Thesis, Graz University of Technology, Graz, Austria, 2019.

77. Gasser, J. Designing Smart Services in Production. Master's Thesis, Graz University of Technology, Graz, Austria, 2016.

78. Kutej, D. Technology-Triggered Process Improvement in Production. Master's Thesis, Graz University of Technology, Graz, Austria, 2018.

79. Url, P. Designing Smart Information Services in Automotive Production. Master's Thesis, Graz University of Technology, Graz, Austria, 2017.

80. Wernerfelt, B. A resource-based view of the firm. Strateg. Manag. J. 1984, 5, 171-180. [CrossRef]

81. Vorraber, W.; Vössner, S. Modeling Endogenous Motivation and Exogenous Influences in Value Networks of Information Service Systems. JCIT 2011, 6, 356-363.

82. Partsch, H.A. Requirements-Engineering Systematisch; Springer: Berlin/Heidelberg, Germany, 2010.

83. Rupp, C. Requirements Engineering und-Management; Carl Hanser Verlag: München, Germany; Wien, Austria, 2009.

84. Gordijn, J.; Yu, E.; Van Der Raadt, B. E-service design using $\mathrm{i}^{*}$ and e/sup 3/value modeling. IEEE Softw. 2006, 23, 26-33. [CrossRef]

85. Vroom. Work and Motivation; Wiley: Hoboken, NJ, USA, 1964.

86. Porter, L.W.; Lawler, E.E. Managerial Attitudes and Performance, 1st ed.; Richard D. Irwin: Homewood, IL, USA, 1968; Volume 23, p. 209, ID: AC03757169. [CrossRef]

87. Kelman, H.C. Processes of opinion change. Public Opin. Q. 1961, 25, 57. [CrossRef]

88. Bocken, N.; Short, S.; Rana, P.; Evans, S. A literature and practice review to develop sustainable business model archetypes. J. Clean. Prod. 2014, 65, 42-56. [CrossRef]

89. Müller, M.; Schindler, C.; Slany, W. Engaging students in open source: Establishing FOSS development at a university. In Proceedings of the 52nd Hawaii International Conference on System Sciences, Grand Wailea, Maui, HI, USA, 8-11 January 2019; pp. 7721-7730.

90. Schierlinger-Brandmayr, F. Engineering of a Toolkit to Support Ecosystem Analysis and Design. Master's Thesis, Graz University of Technology, Graz, Austria, 2019.

(C) 2019 by the authors. Licensee MDPI, Basel, Switzerland. This article is an open access article distributed under the terms and conditions of the Creative Commons Attribution (CC BY) license (http://creativecommons.org/licenses/by/4.0/). 